\title{
Child Poverty Measurement in the UK: Assessing Support for the Downgrading of Income-Based Poverty Measures
}

\author{
Kitty Stewart ${ }^{1}$ (D) $\cdot$ Nick Roberts $^{2}$
}

Accepted: 14 March 2018 / Published online: 17 May 2018

(C) The Author(s) 2018

\begin{abstract}
In 2016 the UK's Conservative Government radically changed the official approach to child poverty measurement, scrapping targets for income poverty and material deprivation and introducing instead indicators of household 'worklessness' and children's educational attainment at age 16. This paper seeks to assess the extent of support for this move among a range of national experts. The paper briefly reviews the way that poverty has been conceptualized by researchers going back to Booth and Rowntree, before going on to examine 251 responses to a 2012-2013 UK government consultation on child poverty measurement. By drawing on the consultation, the paper is able to consider the views of those working in local authorities, children's charities and frontline services as well as academic researchers. In doing so, it seeks to contribute to the literature on poverty measurement by considering a wider set of voices than are often heard. The paper identifies very clear and broad-based support for an approach to poverty measurement that has income and material deprivation at its heart. Out of 251 responses, just two advocate removing income from poverty measurement. Responses also overwhelmingly reflect a relative understanding of poverty. There is fairly limited support for a multidimensional approach, and the paper reflects on why this might be, given a shift to more multidimensional thinking about poverty globally. It concludes that poverty measurement is highly political: what is measured drives policy, and preferences for indicators therefore reflect, at least in part, current political concerns about how best to hold government to account.
\end{abstract}

Keywords Child poverty · Measurement · Consultation · Income poverty · Multidimensional poverty $\cdot$ UK government

Kitty Stewart

K.J.Stewart@1se.ac.uk

Nick Roberts

nicholasjproberts@gmail.com

1 Department of Social Policy, London School of Economics and Political Science, Houghton Street, London WC2A 2AE, UK

2 Kantar Public, 6 More London Place, London SE1 2QY, UK 


\section{Introduction}

The UK has seen rapid and substantial change in its approach to the official measurement of child poverty in the past two decades. After Prime Minister Tony Blair's pledge in 1999 to eliminate child poverty in a generation, in 2003 the UK introduced a suite of four official child poverty indicators, with interim targets attached. All four reflected household material circumstances, using household survey-based measures of income and material deprivation. In 2010 the four measures and their targets were enshrined in law under the terms of the Child Poverty Act 2010, making it a legal duty for national government to ensure that child poverty fell below stated levels by 2020 , and requiring corresponding action from local government and other partners.

In 2015 the newly elected Conservative Government announced plans to change the terms of the Child Poverty Act, removing all income and material deprivation based indicators and targets from the act and replacing them with indicators (but not targets) of household 'worklessness' and children's educational attainment at age 16. The 2016 Welfare Reform and Work Act passed these proposals into law. Amendments put forward by the House of Lords ensured that the government must still publish the scrapped measures annually, but formal reporting to parliament will now focus on worklessness and educational attainment.

The switch from a legal requirement to meet targets for reducing income poverty and material deprivation, to the effective scrapping of income from official poverty measurement altogether, is quite a dramatic one. The aim of this article is to assess the extent of support for such a move among a range of what we might call 'experts'. In particular, the article explores the responses to a government consultation into the child poverty measures conducted by the Conservative-Liberal Democrat Coalition Government in 2012-2013. Using a Freedom of Information request, we obtained access to 251 of the 257 responses to this consultation, from individuals and organizations with a wide range of experience and expertise, including academics, local authorities, frontline services, children's charities and individuals with personal experience of poverty. Examining how the proposed measurement changes sit within these wider views seems important as a matter of record, given a shifting landscape and often confused rhetoric with regard to official approaches to child poverty measurement. We also seek to provide a wider international audience with insight into perspectives on the issue among a range of UK stakeholders.

We focus on three central questions, motivated by the changes to the Child Poverty Act and the justifications given for them. First, was there any support among respondents for a move to abandon income-based poverty measures? Second, was there support for a move towards a multidimensional approach to poverty measurement, keeping income measures but also including other aspects of what children need to thrive? And third, within an income-based approach, was there an appetite for changes to the specific indicators used; in particular, for downgrading the relative measure and placing a stronger focus on an 'absolute' or fixed threshold measure?

The article begins with some background about the introduction and subsequent scrapping of the UK's child poverty measures. We then briefly review academic debates on the conceptualization, definition and measurement of poverty, focusing on our three key questions. This provides context about perspectives on child poverty measurement in the published literature on the topic, within which we situate the subsequent discussion of the consultation responses. 


\section{Official Measurement of Child Poverty in the UK Since 1999}

The origin of the UK's official child poverty targets lies in Tony Blair's pledge in his early years as Prime Minister to "eradicate child poverty in a generation" (Blair 1999), and his subsequent requirement that the DWP start developing trackable measures to hold government to account in achieving this. A consultation on measurement was conducted in 2002, followed by further methodological work by a technical working group. These exercises ultimately led the government to adopt what they called a "tiered approach," comprising three inter-related indicators "capturing different aspects of poverty whilst respecting the finding of our consultation that income is at the core of people's conception of poverty" (DWP 2003, p. 1). The indicators were:

- An 'absolute' low income measure (below $60 \%$ of the median equivalised household income in 1998/99, before housing costs (BHC), uprated with price inflation) - "to measure whether the poorest families are seeing their incomes rise in real terms".

- A relative low income measure (below $60 \%$ of contemporary median equivalised household income BHC) — "to measure whether the poorest families are keeping pace with the growth of incomes in the economy as a whole".

- A combined measure of material deprivation and low income (below $70 \%$ of median income BHC and falling below a material deprivation threshold) — "to provide a wider measure of people's living standards".

For child poverty to be said to be falling, all three indicators needed to be moving in the right direction (DWP 2003). Targets for each were set for 2020/2021, along with interim targets for 2004/2005 and 2010/2011. In 2010, under Gordon Brown's premiership, and in one of the last pieces of legislation before Labour lost office, the Child Poverty Act enshrined this approach in law. Four child poverty targets were established to be met by 2020/2021, one for each of the original three indicators plus a target for:

- Persistent poverty (children living in households below the relative income poverty line in three of the past 4 years).

The Act also introduced requirements for the UK Government (and the Scottish and Northern Irish Ministers) to publish a child poverty strategy, set up an advisory Child Poverty Commission, and report annually on progress. Further, it placed duties on local authorities and other "delivery partners" in England to conduct a local needs assessment, produce a local child poverty strategy and to work together to tackle child poverty (Kennedy 2014).

Thus Labour settled on, and used legislation to protect, a suite of indicators which equated poverty with a lack of material resources. This is not to suggest that material deprivation was the only aspect of childhood circumstances that Labour administrations were targeting. Indeed, in 1999 the government announced an annual audit of "the complex, multidimensional problems" of poverty and social exclusion-Opportunity for All (OfA) (DSS 1999). Wide-ranging indicators of child health, education, housing quality and parental employment were selected and published in annual reports until 2007 and online thereafter. The two indicators the Conservative Government would later prioritise-children in workless households and educational attainment at age 16-were both on the list (see e.g. DWP 2007). The term "poverty and social exclusion" was used repeatedly in the OfA reports as an umbrella term for multidimensional forms of disadvantage, with the first 
report defining poverty itself very much in such terms: "Lack of income, access to goodquality health, education and housing, and the quality of the local environment all affect people's well-being. Our view of poverty covers all these aspects" (DSS 1999, p. 23). It appears to have been the process of consultation in the wake of Blair's pledge that led to the narrower focus of the targeted measures on low income and material deprivation. The approach adopted in 2003 was one of four options set out in the 2002 consultation document, with two options explicitly multidimensional, combining indicators including low income, worklessness and educational attainment. The government reported that there was no clear consensus on the way forward, but that there was a general acceptance that income needed to be central, considerable support for incorporating direct measures of material deprivation, and also widespread backing for the continued use of the OfA indicators alongside whichever measure was chosen (DWP 2003).

The Child Poverty Act passed through Parliament in 2010 with cross-party support, but there were dissenting voices, giving a flavour of possible changes to come. The Conservatives voted in favour and pledged commitment to eradicating poverty, but noted their disagreement with the choice of indicators. Lord Freud, then Opposition Spokesman on Welfare Reform, argued that the indicators were "poor proxies for achieving the eradication of child poverty", and said the Conservatives would focus on "tackling the causes rather than the symptoms of poverty" (HL Deb, 15 January 2010, cc25-27). The Liberal Democrats expressed strong support for the commitment to end child poverty, but raised a series of smaller concerns, including whether the 'absolute' target was necessary (Kennedy 2014).

In office from May 2010, the Conservative-Liberal Democrat Coalition Government used their first child poverty strategy (required under the terms of the Child Poverty Act) to add a supplementary 'severe poverty' measure (though without targets) - children in households below 50\% median income and below a material deprivation threshold (HM Government 2011). But the strategy also reiterated the government's conviction that "poverty is about far more than income" (p. 2) and called for a new approach "which places the emphasis on tackling the powerful drivers that keep the most disadvantaged families from leaving poverty behind (p. 4). In 2012 a new consultation document, Measuring Child Poverty, set out the government's concerns with the existing approach to measurement (HM Government 2012). First among these, creating "the urgent need to rethink our approach to measuring child poverty" (p. 10), was the fact that relative income poverty had fallen during the recession that followed the 2007 financial crisis, in part because of declining median living standards, giving a spurious impression of progress. It was also argued that the measures focused too heavily on income, failing to "capture the full experience of growing up in poverty or the barriers to getting out of poverty" (p. 13). The paper proposed a shift to a multidimensional measure, and asked for views on the inclusion of particular factors in such a measure.

The consultation received 257 responses from individuals and organisations with a wide range of experience and expertise-academics, think tanks, local authorities, churches, children's charities, front line workers and individuals. The responses were summarised very briefly (and, it turns out, somewhat misleadingly) in an Appendix to the 2014-2017 Child Poverty Strategy (HM Government 2014). But the issue was subsequently set aside for the remainder of the administration, amid reports of internal disagreement about next steps ('Plans to change child poverty measures hit impasse,' The Guardian, Friday 14 February 2014).

Soon after the Conservatives returned to power with a majority government in May 2015, Secretary of State for Work and Pensions Iain Duncan Smith announced a "new and strengthened approach to tracking the life chances of Britain's most disadvantaged 
children" (DWP 2015). A DWP press release stated that the "current child poverty measure-defined as $60 \%$ of median income-is considered to be deeply flawed and a poor test of whether children's lives are genuinely improving". It proposed the introduction of new core indicators of 'worklessness' and educational attainment, and to develop "a range of other measures and indicators of root causes of poverty, including family breakdown, debt and addiction, setting these out in a children's life chances strategy". In Autumn 2015 these changes were published as amendments to the Child Poverty Act within the Welfare Reform and Work Bill. These amendments would retrospectively rename the Child Poverty Act 2010 as the Life Chances Act 2010 while repealing much of its content, including the four targets, the requirements to have UK and local authority child poverty strategies, and the duties on local authorities to conduct child poverty needs assessments. In their place, there would be a new requirement to report annually (but without targets) on children living in workless households, children in long-term workless households, and educational attainment at age 16 of all children and of disadvantaged children.

This article considers how these changes in the official approach to the measurement of poverty - the decision to move beyond income to a more multidimensional set of indicators, and the more radical decision to drop income and material deprivation indicators altogether - sit within wider understandings of poverty and its measurement in the UK. Responses to the 2012-2013 consultation provide an excellent source of data on which to draw for this end, bringing in voices beyond academia. First, though, we briefly review academic disagreement and consensus on the issue.

\section{Social Scientists' Understanding of Poverty}

\subsection{Fundamentally About a Lack of Material Resources?}

'Poverty' is frequently said to be a socially constructed and contested concept; it means what we construct it to mean, and not everyone agrees. This is illustrated by the extensive academic debates on the subject. Nonetheless, we suggest that there has been a broad consensus in the UK literature around an understanding of poverty as either a lack of material resources, or an inadequate standard of living driven by a lack of material resources.

Lister (2004) reminds us that concepts, definitions and measures of poverty are not the same thing and that it is helpful to be clear about which we mean. A concept is "in essence... about the meanings of poverty-both to those who experience it and to different groups in society" (p. 4). The question of whether poverty is about material resources, or about something else as well, or instead, is a conceptual question. A definition is a more precise statement that distinguishes being in poverty from not being in poverty; for example, if the concept is a lack of resources, this lack could be defined in absolute or relative terms. Measures of poverty operationalize the definition so that we can put numbers on the extent or depth of poverty. In practice, as Lister points out, much academic work has focused on definition and measurement rather than conceptualization. It may be that this is precisely because the concept itself is largely shared.

Charles Booth's survey of London in the 1880s was the first attempt to reach an evidence-based estimate of the extent of poverty in the UK. In doing so Booth established the principle of a "line of poverty", reflecting a concept of poverty as low income relative to needs: "By the word poor I mean to describe those who have a fairly regular though bare income, such as $18 \mathrm{~s}$ to $21 \mathrm{~s}$ per week for a moderate family, and by 'very poor' 
those who fall below this standard, whether from chronic irregularity of work, sickness or a large number of young children" (Booth talking to the Royal Statistical Society in 1887; quoted by Glennerster 2004). As Gillie (1996) makes clear, this rough poverty line was an illustrative device only, used by Booth to help present his findings, rather than a means to identify the poor; classification was based on the subjective impressions of the School Board employees and survey enumerators who visited each household, and Gillie's research reveals that overcrowding and the employment of servants were the main criteria Booth used in practice, not earnings. Nonetheless, these subjective assessments were clearly aimed at capturing material living standards in the household, including housing conditions, rather than (for example) employment, child health or education attendance, while Booth's illustrative income lines reflected his belief that low income was the main driver of poor material conditions, with "drink and thriftlessness" the problem for a minority (Booth 1897, vol 1, pp. 147-148; cited by Gillie 2000).

Seebohm Rowntree took a similar "visual identification" approach to identifying the poor in his 1899 study of York (Veit-Wilson 1986, p. 92), asking his investigators to note down whether families were "living in obvious want and squalor" (Rowntree 1901, p. 114). Income itself was not a criterion for this assessment, as Veit-Wilson emphasizes. Like Booth's, Rowntree's income-based poverty line was constructed after the survey, mainly to distinguish between families in 'primary' and 'secondary' poverty-those who could not afford "necessities" on their income, and those who could, were they not spending money on other things, useful or otherwise. Rowntree's definition of poverty, one of the first such attempts at definition, focuses on the 'primary' poor and the concept of inadequate income relative to needs: families were poor if their total income was insufficient to enable them to purchase what they needed to maintain physical efficiency. ${ }^{1}$ This "subsistence standard" approach became widely adopted thereafter, first by social scientists and then by government (Abel-Smith and Townsend 1965). Rowntree's second survey, in 1936, widened the understanding of necessities to include other needs, including a radio, a newspaper and presents for children, but the underlying concept of poverty as insufficient material resources to meet one's needs (however defined) remained (Rowntree 1941). ${ }^{2}$

After Booth and Rowntree, this concept of poverty appears to have become so widely accepted that many authors have dealt with the issue in depth without ever spelling out that this is how they understand it. Abel-Smith and Townsend's own 1965 work opts to use National Assistance rates as the poverty line and includes a discussion of whether income or expenditure data gives a more accurate measure of standard of living, but leaves the idea that poverty is about inadequate material resources as implicit. Hills (2004) and Alcock (2006) contain extended discussion of different approaches to poverty definition and

\footnotetext{
1 Rowntree's definition is credited by Abel-Smith and Townsend (1965) as being the first such attempt to define poverty, though Gillie (2000) points to very similar definitions presented previously by others, such as Frederick Scott. Gillie reveals that Scott conducted his own survey of poverty in two districts in Manchester and Salford in the 1880s, comparing family incomes to the cost of necessities in a similar (albeit more limited) way to Rowntree's approach a decade later. Scott defined poverty as "inadequacy of income to supply the minimum of food necessary for the proper nourishment of the body and for the provision of other necessaries, such as clothing and shelter" (Scott 1889, p. 97).

2 Veit-Wilson (1986) argues that Rowntree's 1941 report shows that his concept of an adequate level of living included many factors other than income-conditions of housing, health, education, recreational and leisure activities. He suggests that later writers, including Townsend, make a mistake in quoting from Rowntree "only the statistics of the poor who also have low incomes instead of giving correctly the statistics of all the poor" (p. 90). But Rowntree (1941) keeps a clear distinction between Part I on poverty and "Life Below The Minimum" and Part II on housing, health and education, where he discusses, for example, "the relation between poverty and health" (p. 281).
} 
measurement that take as read that the concept of interest is a lack of material resources. Niemietz (2011) builds an extended critique of the UK's official approach to poverty measurement, and the relative income measure in particular, but does not question the view that poverty is about material resources.

Townsend (1979) made an enormously influential contribution in taking an explicitly relative approach to thinking about needs, and also called for a wider concept of 'resources' to replace 'income' (p. 57), defining individuals and groups as living in poverty "when they lack the resources to obtain the types of diet, participate in the activities and have the living conditions and amenities which are customary... in the societies to which they belong" (p. 31). Yet mostly what he lists under the heading of 'resources' are material resources, including income, assets and home production. He does also add "the value of public social services" (health and education), hinting at a multidimensional approach, but this is not developed in his 1979 book. In later work he distinguishes clearly between concepts of poverty and ("as important") wider deprivation, including social deprivation (isolation, discrimination, lack of opportunities for education or employment), arguing that poverty (a lack of resources) is one of the factors that can lead to deprivation: "[Deprivation] turns on the level of conditions or activities experienced, [poverty] on the incomes and other resources directly available" (Townsend 1987, pp. 139-140). ${ }^{3}$

Ringen (1988) points to the distinction between indirect and direct concepts of poverty, the former focusing (like Townsend) on the resources we need to reach a given standard of living, and the latter (like Booth's and Rowntree's initial observational surveys) on the standard of living itself. Income poverty lines tell us about resources, but Ringen argues that income is both logically flawed and inaccurate as a measure of standard of living, which he thinks is the more appropriate focus in European welfare states. Developing this theme, other researchers have proposed direct measures using indicators of material deprivation (e.g. Mack and Lansley 1985) or measures which combine income and material deprivation, sometimes called a 'consistent poverty' measure (e.g. Callan et al. 1993; Nolan and Whelan 1996, 2011). Callan, Nolan and Whelan's work informed the Irish Anti-Poverty Strategy and subsequently inspired the 'combined' indicator in the UK suite of four. As well as capturing deprivation directly, the consensual approach taken in these studies means popular opinion rather than experts determines what is necessary. ${ }^{4}$ Nonetheless, the focus remains overwhelmingly on material well-being.

Lister (2004) pushes us to think about the "relational/symbolic" aspects of poverty (p. 7), and its "non-material as well as [its] material manifestations". Drawing on Jones and Novak (1999), she writes that "Poverty has to be understood not just as a disadvantaged and insecure economic condition but also as a shameful and corrosive social relation" ( $\mathrm{p}$. 7). This focuses us not only on the question of whether an individual is or is not considered to be in poverty, but also on everyday interactions between those in poverty and wider society, including the language and treatment experienced from politicans, officials, the

\footnotetext{
3 The definition of poverty adopted by the Council of Europe in 1985 is interesting in explicitly defining resources more widely than the material: "persons, families and groups of persons whose resources (material, cultural and social) are so limited as to exclude them from the minimum acceptable way of life in the Member State in which they live" (EEC 1985). The wider concept appears to have had limited impact on measurement approaches, though low work intensity is frequently included, as it is in the 2020 poverty and social exclusion target adopted by the EU in 2011 (European Commission 2011).

${ }^{4}$ It is standard practice in using material deprivation indicators to count households as deprived of a given item only it is an 'enforced' lack-i.e. households report that they lack the item because they cannot afford it, not for other reasons (see Nolan and Whelan 1996). Hence although some indicators can be seen as capturing social deprivation (e.g. not having friends round to tea), material deprivation is the cause.
} 
media and others. However, Lister points out that while non-material aspects such as a lack of voice, respect and self-esteem can all be part of people's experience of poverty, these things are not unique to the condition of poverty, but are associated with other oppressed minorities. In her view, too, poverty is understood as being about a material core, and she argues for a definition that captures this.

\subsection{Multidimensional Approaches}

In academic debate about poverty in the UK, then, we suggest that discussion has focused predominantly on definitions and measures, with widespread underlying agreement that the concept in question is about material living standards. This consensus crumbles when we step further afield. In the development literature poverty is increasingly understood as multidimensional in a substantive sense, with measures required to capture wider deprivations that may have other drivers than a lack of material resources.

Amartya Sen's work has been seminal in this regard. Like Ringen, Sen points out that material resources are a means to an end, not an end in their own right: they matter because of the kind of life they enable people to lead. But Sen's idea of the relevant goal is broader than standard of living: he argues that to lead a good life people need to have the 'capabilities' to achieve certain 'functionings'- "from being well nourished or avoiding premature mortality to taking part in the life of the community and developing the skill to pursue one's work-related plans and ambitions" (Sen 2011, p. 233). Poverty should therefore be defined not narrowly in terms of material resources but more broadly as capability failure, bringing access to other goods, such as health care and education, into focus. Note that Sen is clear that the capability approach "does not involve any denial of the sensible view that low income is clearly one of the major causes of poverty, since lack of income can be a principal reason for a person's capability deprivation" (Sen 2001 p. 87). People can be capability deprived without having a low income, for example because of discrimination, or because services are not available locally. Nevertheless, low income remains one key cause of capability deprivation.

The work of Alkire, Foster and colleagues at the Oxford Poverty and Human Development Initiative (OPHI) builds on Sen's framework to develop multidimensional poverty measures, rooted, like Sen's, in a broad vision of the good life, and encapsulating multiple forms of deprivation. Motivating their approach, they quote Sen (2000): "Human lives are battered and diminished in all kinds of different ways, and the first task... is to acknowledge that deprivations of very different kinds have to be accommodated within a general overarching framework" (quoted by Alkire et al. 2015, p. 4). They go on to argue that "If poverty is understood to be a shortfall from well-being, then it cannot be conceptualized or measured in isolation from some concept of well-being" (pp. 3-4) [italics added]; "poverty measures... must reflect the multifaceted nature of poverty itself' (p. 4).

Alkire and Foster's empirical work captures measures of material resources alongside wider domains, as do the most well-known practical operationalizations of Sen's approach, the United Nations Development Programme (UNDP)'s Human Development Index and Multidimensional Poverty Index, both of which combine indicators from three dimensions-education, health and standard of living (e.g. UNDP 2015). The European Union has also committed to a multidimensional measure for their 2020 'poverty and social exclusion' target, though this only adds household joblessness to measures of income poverty and material deprivation (European Commission 2011). 
A separate driver for multidimensional indicators, with particular reference to children, has been the United Nation's commitment to a human rights approach, shaped by the Convention on the Rights of the Child (CRC). In 2006 the UN General Assembly adopted an international definition of child poverty which is rooted in the CRC and is unambiguously multidimensional: "Children living in poverty are deprived of nutrition, water and sanitation facilities, access to basic health-care services, shelter, education, participation and protection". Attempts to develop multidimensional indices of child poverty appropriate for this definition have followed (e.g. Roelen et al. 2009; Gordon and Nandy 2012).

In light of this wider context, can the changes to the Child Poverty Act be seen as an overdue attempt by the British government to take a more expansive approach to thinking about poverty? Three points are important.

First, like Sen, Alkire and Foster's objection to focusing poverty measurement on material resources is that this excludes other forms and causes of deprivation, rather than that resources are themselves not important. An attempt to broaden the UK's approach in line with wider global thinking would have involved adding to, rather than replacing, the measures in the Child Poverty Act. Indeed, the multidimensional option proposed in the original 2002 consultation-combining indicators of low income, worklessness and low educational attainment-would have made a more coherent alternative measurement approach than a decision to focus only on the latter two variables.

Second, reserving the term 'poverty' to mean a short-fall in material resources (as we argue has been the accepted practice in the UK) rather than OPHI's "shortfall from well-being" should not be seen as a rejection of the concept of well-being, or of the idea that there are many ways in which lives can be diminished; it is simply a different use of language. Veit-Wilson (1986) argues that discussion about action would be helped if we agreed to use the term 'deprivation' for "the concept of unmet need" and 'poverty' for "the condition of lacking money resources" (p. 94) Townsend (1987) uses the terms in a similar way, as noted above. Lister (2004) concurs, arguing that defining poverty as capability failure "is in effect conflating a wider condition... be it capabilities, quality of life, well-being or social quality-with what is conventionally understood as one aspect of that condition, namely being in poverty or not" (p. 18). She suggests we retain the more specific focus of the term 'poverty' by using 'capability deprivation' to refer to deficiencies in other domains.

Third, differing preferences over the use of the word 'poverty' plausibly reflect different contexts in which poverty measurement takes place, and the policy focus that the choice of indicators drives. We know that "measures of child poverty undoubtedly influence policies to reduce child poverty" (Alkire and Roche 2012, p. 103). Initiatives such as OPHI and the UN HDI push back against a long-standing dominant focus by organisations like the World Bank on economic growth as the central goal for development. In a context in which reductions in dollar-a-day poverty are seen as evidence of "pro-poor growth" even where social spending remains low and public services poor quality, the call for multidimensional poverty measures is a demand for a wider view of development which encompasses broader human flourishing, and for corresponding attention to policies which go beyond growthmaximization. By contrast, in the UK, public services are well-established and universally accessible. This is not to say that access to the highest quality provision is equal, nor that outcomes are fair-we know that is not true, thanks to a range of administrative and survey datasets such as the National Pupil Database and the Health Survey for England, and the Opportunity for All reports recognized and reported on these wider deprivations and inequalities. But the complexity of factors influencing poor outcomes in education or health makes it harder to pin down the role of government policy choices. Given a social security 
system with near comprehensive reach and the existence of robust microsimulation models such as those used by the Institute of Fiscal Studies, policy impact on income poverty is easier to isolate. In this context, a desire to keep poverty measures focused on material resources alone may reflect a concern to keep a clear spotlight on inadequate household financial resources, and not to allow income poverty to be diluted or lost within a broader set of indicators.

\subsection{0\% Median: A Deeply Flawed Measure?}

There is growing agreement in the academic literature that the distinction between relative and 'absolute' definitions of poverty is overplayed and debates between them sterile (Lister 2004; Alcock 2006). Joseph and Sumption's (1979) definition of an absolute standard- "one defined by reference to the actual needs of the poor and not by reference to the expenditure of those who are not poor"-is often set up in opposition to Peter Townsend's classic relative definition, in which needs are rooted what is normal in the society in which a person lives, as set out above. But as many writers have pointed out, all measures must surely have reference to social standards: "universal absolute needs... can only be satisfied in particular historical and cultural contexts" (Lister 2004, p. 36). Joseph and Sumption (1979) argue that "a family is poor if it does not have enough to eat", but beyond a very bare subsistence level food is socialized-we eat "food not nutrients" (Dowler and Leather 2000 , p. 208). Adam Smith made a similar point in relation to clothing, famously including as a "necessity" a linen shirt, because "creditable day labourers" would be ashamed to appear in public without one (1776, p. 691). So indeed did Booth, writing that "very poor" families were those whose means were insufficient "according to the usual standards of life in this country" (Simey and Simey 1960, p. 279; and see Veit-Wilson 1986).

That human material needs - and therefore poverty - can only be defined in relation to social norms still leaves the question of measurement wide open. The UK's outgoing 'headline' measure of $60 \%$ of equivalised contemporary median income continues to be used as the main poverty indicator in the European Union. Is it nonetheless "deeply flawed", as the Coalition Government argued (DWP 2015)? Two main critiques have been levelled at the indicator.

First, it is arbitrary: why $60 \%$ ? Why not $50 \%$ - as in fact used in some countries (e.g. Australia) and in many OECD publications (e.g. OECD 2015)? Why not 70\%, or indeed any other number? Niemietz (2011) argues that the relative line is used without evidence as an "approximation of the cost of social participation". He advocates instead a measure based on a combination of material deprivation indicators and a budget-standard method that calculates more directly what families actually need. The Joseph Rowntree Foundation have also argued for a budget-standard approach, developing their own poverty indicator based on their Minimum Income Standard, developed and updated on the basis of expertfacilitated focus group discussions about the needs of different family types (JRF 2016).

Second, academics have been alert to the problem the UK government repeatedly highlights in their 2012-2013 consultation document - that in a recession, relative poverty may be seen to fall simply because median incomes fall. There is also the inverse issue, the "Irish paradox", so-called because in the Irish boom of the late 1990s relative poverty rose because incomes at the bottom, while increasing, grew less rapidly than median income (Hills 2004, p. 42).

Nonetheless, there is general agreement that we need a poverty measure that can keep up with social standards in a consistent way over time, if we accept that these standards are 
relevant: "As long as living standards rise over time, poverty standards need to be upgraded over time to remain socially relevant, adjusting in some way to changes in economic circumstances and social perceptions," (Niemietz 2011, p. 66). Hills (2004, p. 63) examines British Social Attitudes data and concludes that people have in mind "a poverty line that rises in real terms in some way over time". This is a clear strength of indicators based on a share of contemporary median income over the longer term, and a drawback with budget standard measures, which need to be updated manually, introducing confusion about what is behind a change in measured poverty - a change in households' circumstances or a change in the line.

Rather than throwing out the $60 \%$ median indicator, then, its limitations point instead to the need to supplement it with additional indicators. This was, of course, the approach originally taken by the DWP and in the Child Poverty Act, which alongside the relative income measure included indicators based on a fixed income line, combined income and material deprivation, and poverty persistence. For a still fuller picture, one might also want to track changes in poverty against alternative shares of the contemporary median (50\% or $70 \%)$.

\section{Views of Wider Stakeholders: The 2012-2013 Consultation on Child Poverty Measurement}

To get a broader perspective than that presented so far, we examine responses to the UK Government's consultation on child poverty measurement, carried out between 2012 and 2013. We briefly outline our method, before examining three key questions.

\subsection{Method}

The consultation was carried out between November 2012 and February 2013. Results were reported a year later in an Appendix to the 2014-2017 Child Poverty Strategy, but only in a highly summarized way (HM Government 2014). ${ }^{5}$ In July 2015 we submitted a Freedom of Information request for the full content of all responses to the DWP. By November we had access to 251 of the full 257 responses to this exercise, sent as scanned electronic files on compact discs. Of the remaining six, four respondents had requested confidentiality and two responses were simply missing. It had taken several attempts to reach the number 251 due in all likelihood to clerical errors: we received (several times) incomplete sets of responses, including one batch which had only been scanned on one side of the paper. Four months on from our initial request, we decided to settle for 251 out of 253 available responses. The bottom row of Table 1 shows how these responses fell across the five main categories adopted by the DWP.

Each consultation response was then read carefully by one of two researchers, and relevant text was recorded in a shared spreadsheet. It became apparent very quickly that this was a qualitative exercise: while there were tick-boxes in the consultation document, many respondents had avoided them, giving their views in comment boxes or covering letters. This is no doubt linked to the fact that the questions asked were not always those that might be considered most salient. For example, the consultation did not ask outright what

\footnotetext{
5 The summary was also misleading, as we discuss elsewhere (Stewart and Roberts 2016).
} 
respondents thought about income measures, or about multidimensionality, but implicitly assumed a multidimensional measure would be introduced. Typical questions included "How should we measure income as a dimension in a future multidimensional measure of child poverty?" and "How important is worklessness as a dimension in a future multidimensional measure of child poverty?" (see Stewart and Roberts 2016 for further discussion of the way the consultation and its questions were framed).

We have therefore sought to interpret the full textual response in order to answer our central questions. In many cases this was straightforward, but often judgement was required. In all difficult cases both researchers independently read the text and then discussed their view, and new response categories were created when the position expressed did not fit with existing options. We also aimed to err on the side of generosity to a position of change from the status quo-for example, agreeing that a response was open to including additional measures as child poverty indicators if the respondent said the dimension was important and did not explicitly state aversion to wider measures of poverty. We have quantified positions in Table 1 but these numbers should be treated as guides rather than precise results. Quotations included below have been selected as representative of wider views (except where they are exceptions, as noted), and we have quoted predominantly non-academic responses to complement the earlier part of the paper.

\subsection{Is There Support for a Move to Abandon Income-Based Poverty Measures?}

Our first question is about respondents' perspective on the place of income-based indicators in poverty measurement. For this question, textual interpretation was straightforward, and results are striking, as summarised in Table 1 . In all, $88 \%$ of respondents made it very clear that they thought income must remain part of poverty measurement, with just $1 \%-$ two respondents-saying no. (The remainder did not express a clearly interpretable view.) Both negative responses came from the academic/think tank category, and only one wanted to move away from material resources altogether. Kristian Niemetz of the Institute of Economic Affairs, whose book on poverty measurement is cited above, called for the use of expenditure instead of income measures, on the grounds that income is an unreliable measure of living standards at the bottom of the distribution, as a result of income volatility and "widespread underreporting of transfer income". Former university researcher Paul Ashton argued that: "given the level of financial support the state provides for low-income families... we should perhaps be looking elsewhere for evidence of child poverty. The most likely candidates are poor housing, poor schooling and poor parenting". These are the only responses of the 251 that fully reject income-based measures.

Among the 'yes to income' respondents, the largest group by far are those who see poverty as, at heart, a lack of material resources. This view was most common among academics/think tanks and national charities and was less dominant among local authorities, frontline services and other responses, though between $40 \%$ and $50 \%$ of respondents in these categories made this same point. A number of these responses, like South Ayrshire Welfare Rights Centre, underlined the distinction between the concept of poverty itself and indicators of risk factors or consequences of poverty:

Poverty is about lack of money.

(Meadows Advice Group; frontline service) 


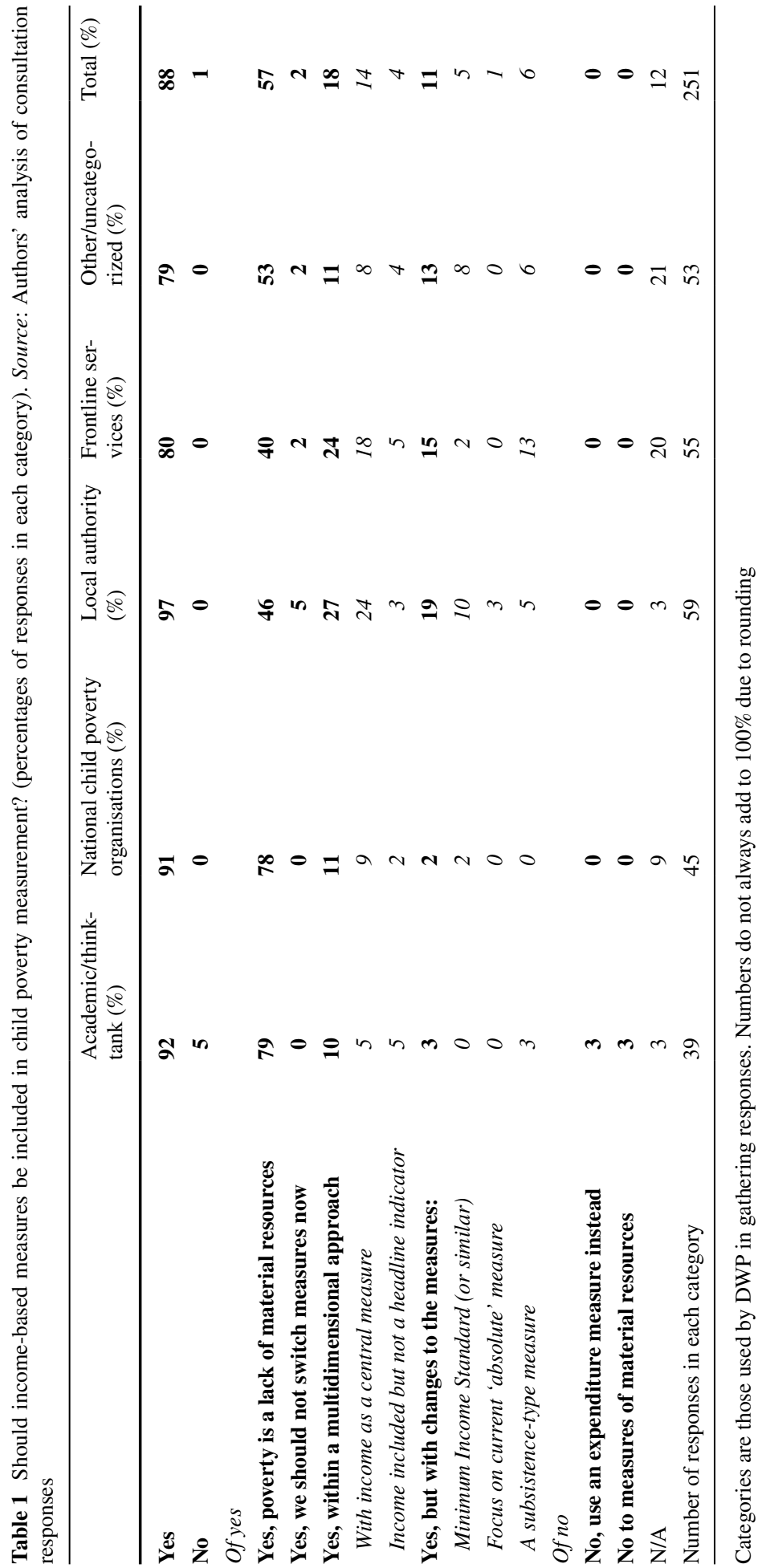


While many families have multiple problems such as addiction issues that need to be addressed these problems are NOT POVERTY. It is also unhelpful to confuse causes of poverty, such as unemployment, and consequences, such as debt, with poverty itself.

\section{(South Ayrshire Welfare Rights Centre; frontline service)}

Largely, responses in this group revealed an informed understanding of the Child Poverty Act. Almost all advocated maintaining the existing approach to measurement, sometimes proposing additional indicators, and often highlighting the way the suite of measures worked together.

A small pragmatic group - five responses-did not engage with debates about the best approach to poverty measurement, but advocated sticking with the current measures to maintain consistency: "It is dangerous to change the roles part way through comparisons. My instinct is to keep with income as the key measure. This at least allows trend analysis" (Fairplay South West; frontline service). Along with a number of others in the larger group just discussed, several of these responses highlight the importance of consistency in holding government to account. As Denbighshire County Council put it: "To alter the definition or measurement of poverty would not enable society to judge whether the UK Government has made any impact on the targets contained in the UK's Child Poverty Act". Many responses also pointed to the importance of the existing measures for international comparisons, and some indicated frustration at a focus on measurement rather than action:

...Given the impact of the recession and of the welfare reform changes on children across the UK, it is imperative that the focus of UK and devolved governments should be on taking concerted action to tackle child poverty, rather than again reviewing child poverty measurement.

\section{(Northern Ireland Commissioner for Children and Young People; other)}

The remainder of responses fit into two groups: those who wanted income measures to continue to be monitored but as part of a multidimensional approach; and those who wanted them to be monitored but preferred a change in the indicators used. These positions are explored in more detail in the following two sub-sections, but we highlight here the small group (ten respondents in all, or 4\%) who wanted to see income measures downgraded within a multidimensional approach-i.e. not given special or 'headline' status. For some, this was driven by a focus on the positives of wider dimensions rather than the limitations of an income measure; the National Council of Women of Great Britain are in this category because of their enthusiasm for measures of additional dimensions, but they still note that "family income levels will always be central to consideration of child poverty". But there are two more critical reasons for wanting income downgraded.

The first concern is that income (even alongside material deprivation indicators) does not adequately capture living standards: thus the National Housing Federation wanted the cost and quality of housing included more comprehensively in measurement. The second concern is that the dominance of income measures leads to a policy focus on one problem at the expense of others. The thinktank Policy Exchange argued that income targets provide perverse incentives to focus on "short-term income distribution rather than on improving broader outcomes that would improve children's lives"; while the Association of School and College Leaders hypothesised that, while money is important, poor budgeting and "purchasing skills" may be the real problem: they cite a headteacher who has noticed children wearing low quality hoodies when warm and waterproof jackets are available at 
the local supermarket for the same price. This last response reveals a desire for measures which focus on parental agency, rather than (or as well as) structural inequalities, as the driver of poor child outcomes. This is, however, an extreme minority position within the responses, reflected just two or three times in all.

\subsection{Multidimensional Perspectives}

Table 1 suggests fairly limited appetite for multidimensional poverty indicators overall, but with more support coming from local authorities and frontline services than other categories. However, we find we can group supporters of multidimensional approaches into three main categories, only the first of which — comprising a small handful of responses - might be seen as reflecting a belief in a truly multidimensional concept of poverty; poverty as a "short-fall from well-being", as Alkire and Foster put it. The thinktank Policy Exchange is one clear example, wanting a poverty measure based on "a number of outcomes that reflect the full range of needs that children have", while the charity Caritas Social Action Network is another (though Caritas also underlines their strong commitment to the existing measures, and opposition to diluting income-based targets and measures):

Poverty is a multi-dimensional and multi-faceted phenomenon, which is not based upon income alone... Factors such as unmanageable debt and poor quality housing... family instability and poor parental health... represent forms of poverty in their own right.

(Caritas Social Action Network; our emphasis)

A subset of this group are responses which support wider measurement approaches from a 'single interest' perspective; one such is the Family Holiday Association, which called for the inclusion of a measure monitoring a child's access to leisure time and recreational activity. These responses demand a broader perspective but from a particular and unidimensional angle.

More common is the second group-responses which referred to the experience of poverty as being wider than material deprivation, or to the need for wider measures to gain a broader understanding of poverty. We distinguish these from the group above because the notion here is not that there are separate deprivations that should be considered poverty in their own right, but that (as Lister argues) poverty may be felt in non-material ways or have non-material consequences, or that the impact of poverty may be worse if other factors are at play.

We welcome the proposal to introduce select other dimensions in the measurement as this recognises that, when combined with low income, other negative experiences such as the household's indebtedness, parental poor health, and poor housing can make children's experience of poverty worse.

(Hyde Group, frontline services)

Note that the idea that the experience of poverty is broader than a lack of income is very widely shared, but only a few responses indicate (or do not explicitly rule out the idea) that the non-material aspects of this experience should be considered part of poverty measurement itself.

For the remaining groups, it seems reasonable to argue that support for multidimensionality reflects neither of the above, but reveals a confused amalgamation of different underlying concepts, combining measures of risk factors for poverty, consequences of 
poverty and sometimes wider aspects of children's well-being too. One such response is from the Centre for Social Justice (CSJ), which called for indicators of what it calls the five "pathways to poverty" (family breakdown, educational failure, worklessness, addiction and debt), explaining that "through our work we have seen how these pathways create poverty, but how they are also its consequences" (our emphasis). The CSJ's influence is clear throughout the consultation document, and the lack of conceptual clarity in the document seems to have led to other confused responses. Questions such as "How important is worklessness as a dimension in a future multidimensional measure of child poverty?" resulted in answers like this, in which an indicator of worklessness is favoured both as a driver of poverty and as a potential influence on children's wider quality of life:

The single most important measure is being in fulltime work and earning a living wage... Work is likely to be the single most effective way out of poverty. Parents' worklessness can also impact on the quality of life of the child as it has potential to cause, or be caused by, other issues such as mental health issues.

\section{(Buckinghamshire County Council)}

It is striking and perhaps surprising that there is so little evidence in the responses of a multi-dimensional perspective on poverty. In part this may illustrate the conventional understanding of what poverty means, as discussed above. Numerous responses emphasise that they would like to see broader indicators tracked but under different headings - wellbeing; factors influencing life chances; risk factors for poverty-but not as indicators of poverty itself. However, the lack of support for a broader approach is no doubt also a reaction to both the political context and the way the consultation document was framed. This could help explain why the results differ strongly from those that have been identified in other exercises; for example, workshops with members of the public conducted in 2010 by the think tank Demos found that an "overwhelming majority" of participants favoured a "Mexican-style" multidimensional approach, including measures of housing and access to health care among other indicators, to the UK suite-of-four (Sodha and Bradley 2010).

For one thing, there is considerable suspicion among consultation respondents about the purpose of the exercise, which may have led some to dig in particularly firmly in support of income alone. As noted earlier, measurement decisions do not take place in a vacuum; it is well understood that these choices shape policy.

Changing measurement of child poverty to look at a number of dimensions will effectively take the focus away from those households that are increasingly struggling for survival based on a lack of sufficient income.

(Riverside Group Ltd, social housing provider; frontline service).

If the government had decided to introduce a multidimensional measure alongside existing measures, and made this very clear, responses may have been different. If there was greater trust in government in relation to action on income poverty, they may have been more different still.

A second issue is that the particular dimensions proposed in the document, which include drug and alcohol addiction, problem debt and family breakdown, are likely to have strengthened opposition to the approach itself. A repeated theme in the responses is a concern about a shift in emphasis towards individual failings and away from structural factors, alongside a related concern about stigmatization. For example, Swansea local authority argues that emphasizing addiction in relation to poverty is "misleading, divisive and linked to the blame culture". The charity Oxfam notes that "to label people as 'workless'... is 
in danger of stigmatizing individuals and shifting attention away from wider conditions that hinder people's ability to move out of poverty". Citizens Advice Bureau (a frontline service) thinks a focus on worklessness "reinforces myths about poverty and agency. Any measure or understanding of child poverty that emphasized this concept would be deeply flawed".

While we count $18 \%$ of respondents overall as interested in a multidimensional approach to poverty measurement in principle (Table 1), support for the specific individual dimensions proposed falls below this for all except housing, which $22 \%$ thought should be included in poverty measurement. Only $13 \%$ of respondents support including indicators of worklessness, $17 \%$ measures of debt, and fewer still education (7\%), family stability (6\%) and addiction $(8 \%)$.

\subsection{Should the Measures be Changed? Support for a Relative Approach}

Our last question is about the "flawed" relative measure. Strong support for keeping income at the heart of poverty measurement could be consistent with a preference for a change in the measurement approach. In practice, there was strong explicit backing for the existing measures. Of 251 responses, 146 (58\%) wanted to keep the Child Poverty Act as it was, implying support for the relative measure among others, with around half of the 146 explicitly underlining that a relative measure is crucial because standards of living change over time. A further 26 wanted to expand the current suite with additional measures, and most of these also express clear support for the relative measure.

A handful of responses in these two groups-five in total-do raise questions about the relative measure related to the recession problem. Labour Frank Field MP, for example, while broadly supportive of the suite of measures, highlighted the rise in foodbanks alongside the fall in relative poverty, and argued that the relative measure "should be labeled with a health hazard warning when used in any meaningful debate". However, most responses were dismissive of this issue, underlining the way the four CPA measures work together. One went further, to suggest that a fall in poverty during a recession is not just a statistical anomaly but captures a meaningful change in relative position:

The decline in relative poverty noted recently can be readily understood by the general public with explanation and is understood by many people living in poverty as expressed by the following quote: 'I don't feel quite so bad about myself now other families are experiencing hard times as well'.

(One Parent Families Scotland; frontline service)

There were 37 responses (15\%) that wanted to change (not just add to) the CPA suite. Did they want to ditch a relative indicator? Not all were clear on this question, but of those that can be interpreted most were not critical of a relative concept, advocating the inclusion of a relative income measure as part of a broader multidimensional basket (nine responses) or calling for a switch to a consensual minimum income standard (MIS) like that of the JRF, which is itself inherently relative (six responses). For some of these, the value of a MIS was that it may be more intuitive to the public, while others wanted to move away from $60 \%$ of median because of the recession concern. All of these, however, retained a common assumption that poverty is a relative concept and that the measure must capture this.

In all, we identify only 12 responses out of $251(5 \%)$ that signaled a preference for a more 'absolute' or subsistence approach to thinking about income poverty. These responses came from a mix of local authorities, frontline services, individuals and a thinktank (the 
CSJ). Interestingly, some of these responses throw up the underlying difficulties in defining poverty as 'absolute'. For example, one individual argues that "income is only important in so far as basic needs can be met" but goes on to include in this "access, of course, to basic tools such as a computer and phone etc.". Birkenhead and Tranmere Children's Centre advocate a switch to an absolute income measure, but go on to note that "families locally find that as everyone is poor in Birkenhead, it is slightly easier to be poor here"-suggestive once more that poverty is a relative concept.

\section{Conclusion}

In the last two decades, the UK's official approach to child poverty measurement has experienced sharp changes of direction, culminating in the effective scrapping of the Child Poverty Act in 2016. Targets and requirements to reduce income poverty were removed from the Act and replaced with indicators (though not targets) of household 'worklessness' and educational attainment at age 16. This paper sought to assess the extent of support for this move among a range of national 'experts'. By examining responses to a government consultation on child poverty measurement conducted in 2012-2013, it explored perspectives among local authorities, charities and frontline services as well as academic researchers.

The paper identifies very clear support in the UK for an approach to poverty measurement that has income and material deprivation at its heart. The vast majority of respondents to the consultation take this view. Just two of 251 responses wanted income excluded from poverty measurement, and one of these would use expenditure measures instead. A further ten responses in all would want to see income measures downgraded-treated as just one indicator among a number of others in a multidimensional approach, not given special or 'headline' status.

Furthermore, responses overwhelmingly reflect a relative understanding of poverty. Even among the minority of responses with concerns about the $60 \%$ median measure, almost all revealed a relative approach, favouring for example the JRF focus group-based Minimum Income Standard, which is strongly linked to social norms.

It is notable that only a handful of responses display a genuinely multidimensional understanding of poverty, in the sense of going beyond material resources to include wider dimensions such as education or health. This is absolutely not to say that there is no support for monitoring a broader set of indicators, as the UK government did for many years with its Opportunity for All reports. Indeed, many respondents underline the importance of doing so, implicitly agreeing with Amartya Sen that "human lives can be battered and diminished in all kinds of different ways". There is resistance, however, to calling these deprivations 'poverty', with calls to keep the concept and measurement of poverty distinct from wider concepts of child well-being or life chances.

In part we suggest that this reflects national convention: we argue that there is a long tradition in British social science research that has conceptualised poverty as a lack of household material resources, and that this view continues to be dominant, even while wider global debates shift towards multidimensional approaches. But in part it is likely to reflect current national political reality. Poverty measurement is highly political: what is measured and reported on is what enables governments to be held to account, and in turn drives policy. In many contexts there are good reasons to widen poverty measurement to include non-monetary dimensions, challenging assumptions that growth is pro-poor as 
long as dollar-a-day poverty is reducing. In the UK, responses to the 2012-2013 consultation reveal concern that to broaden measurement is to detract attention away from income poverty, and away from structural drivers of poverty towards individual failings, just when government benefit reforms are putting pressure on material resources in low income households with children.

Acknowledgements The authors are grateful to the Editor and to two anonymous reviewers for very helpful comments on an earlier draft. They also thank colleagues at the Centre for Analysis of Social Exclusion (CASE), the Department of Social Policy at LSE and the 2016 Social Policy Association Annual Conference for discussions and feedback on versions of the material.

Open Access This article is distributed under the terms of the Creative Commons Attribution 4.0 International License (http://creativecommons.org/licenses/by/4.0/), which permits unrestricted use, distribution, and reproduction in any medium, provided you give appropriate credit to the original author(s) and the source, provide a link to the Creative Commons license, and indicate if changes were made.

\section{References}

Abel-Smith, B., \& Townsend, P. (1965). The poor and the poorest, Occasional Papers on Social Administration, Number 17. London: G Bell and Sons Ltd.

Alcock, P. (2006). Understanding poverty. Basingstoke: Palgrave Macmillan.

Alkire, S., Foster, J. E., Seth, S., Santos, M. E., Roche, J. M., \& Ballon, P. (2015). Chapter 1. In: Multidimensional poverty measurement and analysis. Oxford: Oxford University Press (available as OPHI working paper No. 82).

Alkire, S., \& Roche, J. M. (2012). Beyond headcount: measures that reflect the breadth and components of child poverty. In A. Minujin, \& S. Nandy (Eds.), Global child poverty and well-being: measurement, concepts, policy and action (pp. 103-104). Bristol: The Policy Press.

Blair, T. (1999). Beveridge revisited: A welfare state for the 21st century. In R. Walker (Ed.), Ending child poverty: Popular welfare for the 21st century. Bristol: The Policy Press.

Booth, C. (1897). Life and labour of the people in London, ix: Comparisons, survey and conclusions. London: Macmillan and Company.

Callan, T., Nolan, B., \& Whelan, C. (1993). Resources, deprivation and the measurement of poverty. Journal of Social Policy, 22(2), 141-172.

Dowler, E., \& Leather, S. (2000). Spare some change for a bite to eat. In J. Bradshaw \& R. Sainsbury (Eds.), Experiencing poverty. Aldershot: Ashgate.

DSS. (1999). Opportunity for all: Tackling poverty and social exclusion, First annual report. Cm 4445. London: The Stationery Office.

DWP. (2003). Measuring child poverty. London: Department of Work and Pensions.

DWP. (2007). Opportunity for all: Indicators update 2007. London: Department of Work and Pensions.

DWP. (2015). Government to strengthen child poverty measure. Department of Work and Pensions Press Release. https://www.gov.uk/government/news/government-to-strengthen-child-poverty-measure July $1,2015$.

EEC. (1985). On specific community action to combat poverty (Council Decision of 19 December 1984) 85/8/EEC. Official Journal of the EEC, 2, 24.

European Commission. (2011). Employment and social developments in Europe 2011, DG employment, social affairs and equal opportunities. Luxembourg: Office of the European Union.

Gillie, A. (1996). The origin of the poverty line. The Economic History Review, 49(4), 715-730.

Gillie, A. (2000). Rowntree, poverty lines, and school boards. In J. Bradshaw \& R. Sainsbury (Eds.), Getting the measure of poverty: The early legacy of Seebohm Rowntree. Aldershot: Ashgate Publishing.

Glennerster, H. (2004). The context for Rowntree's contribution. In H. Glennerster, J. Hills, D. Piachaud, \& J. Webb (Eds.), One hundred years of poverty and policy. York: Joseph Rowntree Foundation.

Gordon, D., \& Nandy, S. (2012). Measuring child poverty and deprivation. In A. Minujin \& S. Nandy (Eds.), Global child poverty and well-being: Measurement, concepts, policy and action. Bristol: The Policy Press.

Hills, J. (2004). Inequality and the state. Oxford: Oxford University Press.

HM Government. (2012). Measuring child poverty: A consultation on better measures of child poverty, $\mathrm{Cm}$ 8483. London: The Stationery Office. 
HM Government. (2014). Consultation on the child poverty strategy 2014-17, February 2014. Cm 8782. London: The Stationery Office.

Jones, C., \& Novak, T. (1999). Poverty, welfare and the disciplinary state. London: Routledge.

Joseph, K., \& Sumption, J. (1979). Equality. London: John Murray.

JRF. (2016). UK poverty: Causes, costs and solutions. York: Joseph Rowntree Foundation.

Kennedy, S. (2014). Child poverty act 2010: A short guide. House of Commons Library Standard Note SN/ $\mathrm{SP} / 5585$.

Lister, R. (2004). Poverty. Cambridge: Polity Press.

Mack, J., \& Lansley, S. (1985). Poor Britain. London: George Allen \& Unwin.

Niemietz, K. (2011). A new understanding of poverty, Research monograph 65. London: The Institute of Economic Affairs.

Nolan, B., \& Whelan, C. (1996). Resources, deprivation and poverty. Oxford: Oxford University Press.

Nolan, B., \& Whelan, C. (2011). Poverty and deprivation in Europe. Oxford: Oxford University Press.

OECD. (2015). In it together: Why less inequality benefits all. Paris: OECD.

Ringen, S. (1988). Direct and indirect measures of poverty. Journal of Social Policy, 17(3), 351-365.

Roelen, K., Gassmann, F., \& de Neubourg, C. (2009). The importance of choice and definition for the measurement of child poverty-The case of Vietnam. Child Indicators Research, 2(3), 245-263.

Rowntree, B. S. (1901). Poverty: A study of town life. London: Macmillan.

Rowntree, B. S. (1941). Poverty and progress. London: Longmans, Green and Co.

Scott, F. (1889). The condition and occupations of the people of Manchester and Salford. Transactions of the Manchester Statistical Society, Session, 1888-1889, 93-116.

Sen, A. (2000). A decade of human development. Journal of Human Development and Capabilities, 1(1), $17-23$.

Sen, A. (2001). Development as freedom. Oxford: Oxford University Press.

Sen, A. (2011). The idea of justice. Cambridge: Harvard University Press.

Simey, T., \& Simey, M. (1960). Charles booth, social scientist. Oxford: Oxford University Press.

Smith, A. (1776). An inquiry into the nature and causes of the wealth of nations. London: Electric Book Company.

Sodha, S., \& Bradley, W. (2010). 3D poverty. London: Demos.

Stewart, K., \& Roberts, N. (2016). How do experts think child poverty should be measured in the UK? An analysis of the Coalition Government's consultation on child poverty measurement 2012-13. CASEpaper 197. London: Centre for Analysis of Social Exclusion.

Townsend, P. (1979). Poverty in the United Kingdom. Berkeley: University of California Press.

Townsend, P. (1987). Deprivation. Journal of Social Policy, 15(2), 125-146.

UNDP. (2015). Human development report. New York: UNDP.

Veit-Wilson, J. (1986). Paradigms of poverty: A rehabilitation of B S Rowntree. Journal of Social Policy, $15(1), 69-99$. 